\title{
A Review on Theoretical Development of Vendor-Managed Inventory in Supply Chain
}

\author{
Ran Zhao \\ Jinan University, Guangzhou, China \\ Email: rae1994@163.com
}

How to cite this paper: Zhao, R. (2019) A Review on Theoretical Development of Vendor-Managed Inventory in Supply Chain. American Journal of Industrial and Business Management, 9, 999-1010. https://doi.org/10.4236/ajibm.2019.94068

Received: March 15, 2019

Accepted: April 23, 2019

Published: April 26, 2019

Copyright ( 2019 by author(s) and Scientific Research Publishing Inc. This work is licensed under the Creative Commons Attribution International License (CC BY 4.0).

http://creativecommons.org/licenses/by/4.0/

\section{cc) (7) Open Access}

\begin{abstract}
Vendor-managed Inventory (VMI) is a new inventory operation pattern in the supply chain environment, breaking the traditional independent inventory management pattern. It is a kind of cooperative strategies that improving continuously inventory management, which aims at obtaining the lowest cost for both users and suppliers, manages inventory by suppliers under a common agreement, and continuously supervises the implementation of the agreement and amends the content of the agreement. This paper discusses the existing literature of VMI, and reviews the research of VMI from its connotation, theoretical basis and four stages of development, points out the defects and deficiencies, and puts forward suggestions for further research direction.
\end{abstract}

\section{Keywords}

VMI, Inventory Management, Contract Theory

\section{Introduction}

Organizations are now aware that they have only controlled sub-fraction of the value chain and that opportunities for improvement are quite limited. Therefore, supply chain coordination is the next direction. As a supply chain coordination mechanism, vendor-managed inventory (VMI) has received a lot of attention. In the traditional inventory management system, customers provide orders, suppliers purchase according to orders, and suppliers in the logistics chain only manage their own inventory. The main purpose is to maximize the benefits of individual enterprises, without considering the profitability of upstream and downstream enterprises. And now if enterprises want to maintain competitive advantage, they must have the concept of integration, that is, the idea of supply chain. The supply chain pursues the maximization of the overall interests of all enterprises in the chain, and VMI is a kind of effective management method in 
the supply chain environment. In VMI mode, upstream enterprises such as suppliers manage and control the inventory of downstream customers based on downstream customers' production, operations and inventory information. Due to centralized decision-making and information sharing, VMI's revenue is much higher than that in traditional supply chains.

In the 1980s [1], the VMI system developed by P \& G and Wal-Mart has been successful. Since then, the VMI model has been applied in more and more companies, such as Shell Chemical, Campbell Soup Company and J \& J. Benefits of the VMI include reducing costs of ordering, inventory and transportation, improving production planning, service levels, customer benefits and forecast accuracy. Considering VMI as a collaborative strategy between customers and suppliers that optimizes product availability at minimal cost, suppliers are responsible for the operational management of inventory within a consistent performance target framework and are continuously monitored and updated as needed. Therefore, VMI is best viewed as part of a continuous improvement process rather than as an independent arrangement. The successful application of VMI in practice has aroused the growing attention of academia. In recent decades, a large number of experts and scholars have studied a lot of theoretical results, which has greatly promoted the practice. This paper has carried out a combing of these theoretical studies and made a comprehensive summary of the research status of VMI.

\section{The Connotation of VMI}

Since Magee [2] first proposed Vendor-managed Inventory (VMI), VMI has attracted the attention of academia and enterprise practice. Waller, Johnson \& Davis [3] argues that VMI is a replenishment decisions involving order quantity, shipment and related operations periodically performed that supplier monitors user inventory levels. Ma Shihua [4] believes that VMI is a cooperative strategy that improving continuously inventory management, which aims at obtaining the lowest cost for supply chain partners such as suppliers and users, manages inventory by suppliers under a common agreement, and continuously supervises the implementation of the agreement and amends the content of the agreement. The China's national standard GB/T 18354-2006 "Logistics Terminology" believes that VMI is a management mode through information sharing, and that supply chain and other upstream enterprises actively manage and control the inventory of downstream enterprises according to the sales information and inventory of downstream enterprises.

Among the strategies to improve supplier-retailer partnership, there are many modes such as rapid response QR, continuous replenishment CR and VMI, and VMI is considered as an advanced mode to improve supplier-retailer partnership. VMI is a practice in which suppliers take over the buyer's replenishment strategy to determine the replenishment volume and replenishment time, so as to maintain the minimum and maximum inventory within the specified range. 
Conversely, the buyer shares the data or forecasts of the point of sale so that the supplier can update the data for subsequent transactions. For retailers, it reduces the burden of inventory management; for suppliers, it can optimize inventory management, replenishment, transportation, production and retailer's sales, and reduce the related total cost.

To sum up, VMI is a good inventory management strategy in supply chain. It is based on trust, guaranteed by cooperation, and based on the idea of systematic and integrated management, so that the supply chain system can operate synchronously, and ultimately reduce the inventory cost of both sides to achieve a win-win situation.

\section{Theoretical Basis}

\subsection{Supply Chain Management Theory}

The supply chain is a logistics network consisting of suppliers, manufacturers, warehouses, distribution centers and distributors. It extends the production activities of the enterprises [5]. The basic idea of supply chain management is "horizontal integration", that is, outsourcing parts originally produced by enterprises themselves, making full use of external resources, and forming a horizontal relationship with these enterprises. The purpose of supply chain management is to optimize all links of suppliers, manufacturers, distributors retailers and etc in a chain, so that the means of production can be delivered to consumers at the fastest speed through the production and distribution links. The core concepts of supply chain management are mainly embodied in the idea of system as a whole, the idea of cooperation and the idea of collecting superiority.

The development of supply chain management has created a developing environment for VMI. Vendor-managed inventory applies the capability of supply chain to manage inventory, integrates supply and demand, plans the inventory allocation process of the whole supply chain, realizes the effective operation and management of the supply chain, and optimizes the supply chain as a whole [6]. VMI is a solution about supply chain inventory management that enables suppliers to make replenishment and inventory level decisions based on retailer's point-of-sale data to enable suppliers to plan more effectively and reflect market changes and consumer demand more quickly.VMI has the function of integrated management in supply chain management, which requires close cooperation between enterprises, coordination of supply chain partnership as a whole, and win-win from the overall interests of the supply chain. Therefore, VMI is considered to be one of the best methods of inventory management in supply chain environment.

\subsection{Principal-Agent Theory}

Principal-agent theory is based on asymmetric information game theory, that is [7], the owner entrusts the assets he owns to the operator to operate according to the pre-agreed conditions, the ownership is still owned by the investor, the in- 
vestor enjoys the residual claim right and the final control right according to the share of the investment, and the operator within the authorized scope of the principal, shall exercise the power to possess, dominate, use, and dispose of as necessary on the property of the enterprise according to the rules of the enterprise legal person system. The central task of principal-agent theory is to study how the principal designs the optimal contract to motivate the agent in the environment of conflict of interest and information asymmetry. Because of the information asymmetry between the principal and the agent, the agency relationship between the two is easy to produce a kind of non-cooperation. The principal-agent problem makes the principal have to establish an effective incentive mechanism and supervision mechanism to reduce the agency problem, so that the agent's actions conform to the interests of the principal.

Principal-agent theory is used to analyze the institutional arrangement and design the mechanism of benefit-sharing and risk-sharing among VMI enterprises [6]. VMI emphasizes the intrinsic mechanism of mutual trust and long-term cooperation that belongs to the incentive, punishment and restraint mechanism in principal-agent system. The benefits of maintaining long-term cooperative relationship are far greater than the short-term benefits. The principal-agent system among vendor-managed inventory enterprises is a multi-task principal-agent system requiring finding an appropriate coordination mechanism which is represented by the formulation of contracts between enterprises, including participation constraints and incentive constraints. Coordination mechanism can not only mobilize the enthusiasm of cooperative enterprises and realize income sharing and risk sharing, but also achieve overall benefits.

\subsection{Transaction Cost Theory}

Coase [8] defines transaction cost as the cost of providing goods or services through the market rather than within the company. The fundamental argument of transaction cost theory is to explain the essence of enterprises. Zhang $\mathrm{Wu}$ chang [9] believes that transaction costs are costs that do not exist in the "Robinson Crusoe" economy, including all costs that do not directly occur in the production of materials. Because of the specialization of enterprises and the operation of market price function in the economic system, the phenomenon of specialization has arisen. However, the cost of using market price function is relatively high, and the formation of enterprise mechanism is the organizer formed by human pursuit of economic efficiency. Transaction cost theory uses transaction cost as an analytical tool to study the emergence and development of economic organizations and various institutional arrangements. Asset specificity refers to the degree to which investment is specialized as a special transaction relationship. The high asset specificity refers to the fact that the sunk cost exceeds its specific transaction environment and its value is relatively low.

The upstream and downstream enterprises in VMI need to invest in special assets for better inventory management. The downstream enterprises require the upstream enterprises to invest more in specific areas and increase the value of 
the downstream enterprises. The upstream enterprises require the downstream enterprises to make matching investment in specific assets to serve the upstream enterprises' inventory management [6]. VMI requires network specificity, human assets specificity and material asset specificity. It is necessary to establish close connection and long-term trusting relationships. Investing in these assets, the partnership is likely to continue.

\subsection{Just-in-Time and Zero-Inventory Theory}

Just-in-time production [10] is a new management technology which was first put forward by Toyota Motor Company in 1950s and developed and popularized widely in 1960s. Its name is derived from the most notable feature: jobs that run almost out of stock, and fine-grained synchronization allows materials to arrive only when needed. Just-in-time production is a comprehensive system management project based on market demand, using a pull-type production model like an invisible chain dispatching and affecting the company's work can be smoothly implemented according to the planned process. Zero-inventory theory [11], refers to materials (including raw materials, semi-finished products and finished products, etc.) in the procurement, production, sales, distribution and other one or several operating links, not in the form of warehouse storage, but are in the state of turnover. It does not mean that the storage quantity of some items or items in the form of warehouse storage is really zero. Instead, it realizes the minimization of inventory by implementing specific inventory control strategies. "Zero inventory" means the balance between supply and demand at zero.

Just-in-time production support VMI in production, logistics and distribution, sales links. Minimize the in-process and semi-finished products in the production process, and reduce the inventory of funds; reduce intermediate warehousing and handling links and control the logistics cost to the lowest level; the sales will be produced according to the actual order, and the finished goods inventory will be eliminated. Zero-inventory refers to the fact that logistics does not exist in the form of warehouse storage in the procurement, production, sales, distribution and other links, but in a state of turnover.VMI is a means to achieve "zero inventory" in the supply chain environment. In a sense, VMI does achieve "zero inventory".

\section{Stage of Development}

With the deepening of theoretical research and practice, some new variants of VMI mode have gradually emerged, and it is in constant development, evolution and improvement. According to the different research hot spots, the research on VMI mode in recent years can be divided into four main stages of development. The development stage of VMI mode includes: information sharing, decision analysis and coordination and optimization research between upstream and downstream enterprises in supply chain, and VMI mode of third party logistics participation. The results of the four stages are shown in Table 1. 
Table 1. Stage of development.

\begin{tabular}{|c|c|c|}
\hline Major phases & Contents & Conclusion \\
\hline 1. stage I & 2. information-sharing & $\begin{array}{l}\text { VMI mode can promote information sharing and } \\
\text { reduce bullwhip effect [12] [13]. }\end{array}$ \\
\hline 3. stage II & 4. management decision & $\begin{array}{l}\text { VMI mode is often only beneficial to downstream } \\
\text { members, and the whole supply chain deviates from } \\
\text { Pareto equilibrium [17] [18]. }\end{array}$ \\
\hline 5. stage III & 6. coordinating mechanism & $\begin{array}{l}\text { Contract design establishes coordination mechanism } \\
\text { of supply chain in VMI mode [21] [23]. }\end{array}$ \\
\hline 7. stage IV & 8. third party participation & $\begin{array}{l}\text { A theoretical model of dispersed TPL_VMI and } \\
\text { Supply Hub model is established [25] [26]. }\end{array}$ \\
\hline
\end{tabular}

\subsection{Information-Sharing}

Information sharing is the basis of realizing VMI, which is closely related to the "bullwhip effect". The Bullwhip effect is the phenomenon that demands changes continuously along the upstream of supply chain. VMI is considered to be a new pattern that can weaken the bullwhip effect. Lee et al. [12] considered that in VMI system, information sharing between VMI information systems in supply chain nodes can reduce information distortion during information transfer. Disney and Towill [13] established the VMI_APIOBPCS model through the method of system dynamics, and studied the influence of VMI strategy on the bullwhip effect of the supply chain. The simulation results showed that two factors of the bullwhip effect (rational game and batch order) could be completely eliminated in VMI system, and the influence of price fluctuation caused by promotion on the bullwhip effect was greatly reduced. Ou Weiming et al. [14] studied a two-level supply chain model of a supplier with production capacity constraints and $\mathrm{N}$ retailers. By establishing a game model under VMI mode, it was proved that information sharing could improve the supply chain system and reduce operating costs. Danbin et al. [15] studied the information sharing of production schedule between two suppliers in VMI supply chain with two suppliers and one manufacturer. It was found that the uncertainty of one supplier's production lead time would increase the cost expenditure of suppliers in the supply chain. If at most a single supplier's production lead time was uncertain, information sharing could reduce the minimum cost of suppliers. Otherwise, information sharing can bring value when the change of supplier's lead time is smaller than that of production lead time.

The first phase, from 1958 to 2000, mainly studied the impact of VMI information sharing on the supply chain, such as reducing the bullwhip effect. The VMI mode had been validated in the theoretical community at this stage, which promoted its application in production practice.

\subsection{Management Decision}

After leading into VMI mode into supply chain, the classical EOQ model is no longer applicable. And the management decision mode is improved to form a 
supply chain decision model under VMI mode. Based on the EOQ model, Dong et al. [16] analyzed the inventory decision-making of a two-tier supply chain consisting of a supplier and a retailer after implementing VMI model, and analyzed the profit changes of the participants. Yu Yugang et al. [17] presented a VMI integrated model considering deterioration of final products, in which one supplier manages inventory for multiple retailers. It is found that the deterioration rate of products has a great influence on the inventory cost and inventory strategy of VMI system. Cai Jianhu et al. [18] discussed the VMI model when a supplier faced retailers with multiple points of sales. The supplier was responsible for inventory decision-making and could transfer inventory between different points of sales. This article establishes a Staenberg game between suppliers and retailers. The retailer as a leader is reflected in the decision of the sales price. The results showed that the final suppliers and retailers can reach a sub-game refined Nash equilibrium in which retailers could gain a large profit share. Chen Jie et al. [19] studied the supplier integrated production planning problem based on VMI strategy in supply chain environment. In order to minimize the overall cost of the supply chain, the author had formulated a reasonable production plan for the supplier and the quantity of supply to each distributor in each cycle. According to the theory of information sending and information screening, Liu Dehai et al. [20] analyzed the optimal contract scheme of retailers with corresponding degree of information sharing and benefit sharing, in an attempt to solve the trust problem in the strategic partnership of supplier managed inventory.

The second phase, from 2000 to 2004, mainly analyzed the one-to-one, one-to-many or many-to-one supply chain model, revealed the mechanism of VMI mode failure in practice, and promoted the development of supply chain coordination mechanism under VMI model.

\subsection{Coordinating Mechanism}

In VMI mode, upstream enterprises control the inventory of downstream enterprises, which will inevitably increase the cost of inventory management of upstream enterprises. Therefore, the key to the successful implementation of VMI system is to design a reasonable coordination mechanism to solve the cost transfer of upstream and downstream enterprises, and realize benefit sharing and risk sharing. Scholars' research on coordination mechanism has two main aspects, including performance impact and specific mechanism design. Tang Hongxiang [21] compared the performance of decentralized supply chain with that of VMI supply chain, pointed out that in the absence of effective coordination mechanism, the advantages of VMI cannot be effectively played. The performance of VMI supply chain was further improved by retailers sharing the risk of unsatisfactory sales of suppliers and suppliers undertaking part of the promotion costs of retailers. Dong et al. [16] argued that in the early stage of VMI implementation, due to its disadvantage to suppliers, retailers could consider in- 
creasing purchasing prices to compensate for the increase in inventory costs of suppliers. Other scholars have studied the design of specific coordination mechanisms, and it is necessary to formulate appropriate contracts to effectively coordinate the supply chain. Common contracts include: wholesale price contract, reserve contract, quantity flexibility contract, option contract and revenue sharing contract. Wang et al. [22] discussed the profit distribution between retailers and suppliers when a supplier and a retailer implement VMI mode. The demand of retailers varies with price. Studies have shown that the price elasticity coefficient has a large impact on the overall supply chain and the profit of each member. Liu Pengfei et al. [23] established the VMI coordination model of traditional, Steinberg game and Nash negotiation under the revenue sharing mechanism, and optimized the optimal revenue sharing retention ratio in the model. It is found that the retention ratio of revenue sharing is the lowest and zero in the traditional model, the highest in the Steinberg game model and the middle in the Nash negotiation model. Cao Wujun et al. [24] analyzed the system parameters when the expected profit of the general VMI mode was maximized under the central mode, and analyzed the relationship between the system parameters and price sensitivity factors. A price-sensitive supply chain model with external demand was established. The supply chain model solved the revenue sharing contract in VMI mode by referring to the optimal inventory quantity and the best retail price of the supply chain in the central mode, so that the system performance in VMI mode reaches the Pareto optimal state.

The third phase, from 2004 to 2009, mainly studies the coordination mechanism of supply chain under VMI mode through contract design. The coordination mechanism improved the supply chain imbalance under VMI mode to a certain extent. From the existing research literature, it is not difficult to see that price contract and revenue sharing contract are two kinds of contracts frequently used in VMI interest coordination mechanism.

\subsection{Third Party Participation}

VMI is an advanced inventory management method based on the partnership between upstream and downstream enterprises in the supply chain. However, in the coordination mechanism, suppliers dominate and there is not enough consultation in the decision-making process. Under this environment, VMI may result in damage to the performance of the supply chain. In order to solve this problem, the third party logistics should actively participate in the inventory management of supply chain. When the third party logistics only provides services for VMI between only a supplier and a buyer, the research focuses on the decentralized TPL_VMI mode. Dong et al. [16] discussed the impact of VMI on upstream and downstream members from the profit point of view. It was believed that VMI would always lead to higher profits in the downstream, while upstream profits changes are not necessarily. Zhang Meiyan and Gao Yuanyang [25] improved Dong's model by introducing transportation cost variables, 
pointed out the conditions for supplier's to increase short-term cost, and introduced third-party logistics to optimize VMI model on this basis, which solved the problem of supplier's short-term cost increase and increased the enthusiasm of supplier to participate in VMI. When the third party logistics implements VMI service to multiple suppliers, the most typical mode is Supply Hub. Supply Hub mode is developed from VMI operation mode. It refers to a place or facility that is managed by a third-party logistics company near the manufacturer where all or part of the supply materials are stored. The supply raw materials at Supply Hub can only be paid for when they are actually used. Ma Shihua and Mei Wanxia [26] analyzed the advantages of the Supply Hub model from the perspective of risk. Using the principle of Risk Pooling, it was pointed out that under certain conditions of service level, the operation mode of Supply Hub has lower security inventory than the decentralized operation mode of VMI, resulting in lower inventory costs. And the bigger the Hub is, the more obvious the advantages of the Supply Hub mode of operation are.

The fourth phase, from 2007 to 2010, mainly studies the VMI mode of third party participation, especially the Supply Hub mode, which is the focus of current theoretical circles. The theoretical model of decentralized TPL_VMI and Supply Hub mode is established, which promotes the application of VMI mode in power asymmetric supply chain and provides theoretical support for the development of large-scale Supply Hub mode.

\section{Conclusions}

Inventory management is an indispensable part in the process of production and operation of enterprises, and it is also an important link to realize added value in the value chain. Compared with the traditional inventory management, VMI has the advantages of shortening the lead time of replenishment and reducing the inventory cost. After reading and researching a large amount of literature, VMI has attracted the attention of the business circles and academia as a supply chain-based inventory management method. Many scholars have done a lot of research on VMI from different angles by different methods. This paper reviews the important research results of VMI, including connotation, theoretical basis and development stage.

On the theoretical basis, the development of supply chain management theory has created a development environment for VMI. Principal-agent theory embodies the essence of VMI. Transaction cost theory gives VMI economic driving force. Just-in-time and zero-inventory theory promote the development of VMI. The generation, development and application of these theories have accelerated the development of VMI.

At present [27], the development path of relevant research results can be divided into four main stages: information sharing, management decision, coordination mechanism and third-party logistics. It can be said that the research is carried out along the path from the whole to the individual, and then to the im- 
provement and mode innovation. The research on information sharing among supply chain members under VMI mode mainly focuses on the vertical information sharing between upstream and downstream members. Many scholars have verified that VMI mode can better restrain bullwhip effect than traditional inventory management mode from different angles. There are few studies on horizontal information sharing among supply chain members. Most of the research on management decision-making focuses on one-to-one, one-to-many or many-to-one supply chain models. Few articles are based on the assumption that there are many competing members in the upstream and downstream, which is the biggest difference from practice. For coordination mechanism, the core idea of scholars is to establish supply chain models under centralized and decentralized decision-making. The basic hypothesis of the study is mainly confined to the two-tier supply chain model, and there is little research on the multi-level VMI integration model of multi-level supply chain. The VMI mode of third party participation, especially the Supply Hub mode, is the focus of current theoretical circles. For the Supply Hub model, the main research results focus on the downstream station is the direct station service in the supply chain of downstream production enterprises. For the downstream of the retailer's Supply Hub model, there have been few successful cases in practice, and academic research results are relatively small.

This paper summarizes the research results at each stage of development, and of course finds some defects and deficiencies. The incentive mechanism design of information leakage prevention and information sharing under VMI mode, the design of management decision and coordination mechanism when the upstream and downstream of supply chain are composed of multiple members, the design of management decision and coordination mechanism of multi-level VMI multi-level supply chain and the management decision-making of the third party logistics enterprises participating in VMI mode, these problems are rarely involved in the existing literature. The research is mainly based on the assumption that the two-tier supply chain and the upstream and downstream competitors are single. Therefore, future research can continue to deepen from the above aspects.

\section{Conflicts of Interest}

The author declares no conflicts of interest regarding the publication of this paper.

\section{References}

[1] Cachon, G.P. and Fisher, M. (1997) Campbell Soup's Continuous Replenishment Program: Evaluation and Enhanced Inventory Decision Rules. Production and $O p$ erations Management, 6, 266-276. https://doi.org/10.1111/j.1937-5956.1997.tb00430.x

[2] Magee, J.F. (1958) Production Planning and Inventory Control. McGrew Hill Book Company, New York. 
[3] Waller, M., Johnson, M.E. and Davis, T. (1999) Vendor-Managed Inventory in the Retail Supply Chain. Journal of Business Logistics, 20, 183-203.

[4] Ma, S. and Lin, Y. (2006) Supply Chain Management. Machinery Industry Press, Beijing.

[5] Zhang, B. (2013) Supply Chain Management Theory and Its Application. Enterprise Reform and Management, No. 3, 27-28.

[6] Liu, P. (2011) Theoretical Basis of Vendor Managed Inventory. Journal of Changsha University of Technology (Social Science Edition), 26, 64-69.

[7] Yin, P. (2012) Summary of Principal-Agent Theory. Modern Marketing (Xueyuan Edition), No. 7, 150-151.

[8] Coase, R.H. (1960) The Problem of Social Cost. Journal of Law and Economics, 3, 1-44. https://doi.org/10.1086/466560

[9] Zc. Zhang, W. (2005) Economic Organization and Transaction Cost.

[10] Fullerton, R.R. and Mcwtters, C.S. (2001) The Production Performance Benefits from JIT Implementation. Journal of Operations Management, 19, 81-96. https://doi.org/10.1016/S0272-6963(00)00051-6

[11] Zhang, Y. (2008) A Brief Talk on Enterprise Zero Inventory Management. China Market, No. 2, 22-23.

[12] Cetinkaya, S. and Lee, C.Y. (2000) Stock Replenishment and Shipment Scheduling for Vendor-Managed Inventory Systems. Management Science, 46, 217-232. https://doi.org/10.1287/mnsc.46.2.217.11923

[13] Disney, S.M. and Towill, D.R. (2003) The Effect of Vendor Managed Inventory (VMI) Dynamics on the Bullwhip Effect in Supply Chains. Production Economics, 85, 199-215. https://doi.org/10.1016/S0925-5273(03)00110-5

[14] Ou, W., Hu, Q. and Ma, J. (2006) Research on VMI Strategy and Information Value under Supply Capacity Constraints. Journal of Systems Engineering, 21, 393-397.

[15] Dan, B., Xiao, J. and Wu, Q. (2009) Research on Information Sharing of Production Progress among Suppliers under VMI Mode. Journal of Management Engineering, No. 4, 157-159.

[16] Yan, D. and Ke, F.X. (2002) A Supply Chain Model of Vendor Managed Inventory. Transportation Research Part E, No. 38, 75-95. https://doi.org/10.1016/S1366-5545(01)00014-X

[17] Yu, Y., Liang, L. and Wang, C. (2004) An Integrated Model of Supplier Managed Inventory Considering Deterioration of Final Products. China Management Science, 12, 32-37.

[18] Cai, J., Huang, W. and Cheng, H. (2005) Research on VMI Model of Single Supplier Facing Retailers with Multiple Outlets. Industrial Engineering and Management, No. 5, 56-60.

[19] Chen, J. and Pan, W. (2004) Research on Integrated Production Planning under VMI Strategy. Operational Management, 13, 137-140.

[20] Liu, D., Wang, W. and Wang, X. (2009) Information Screening Model for Selecting VMI Partners in Supply Chain under Incomplete Information. Operational Management, 18, 47-52.

[21] Tang, H. (2004) Impact of VMI on Supply Chain Performance. Chinese Management Science, 12, 60-65.

[22] Wang, Y.Z., Li, J. and Shen, Z.J. (2004) Channel Performance under Consignment Contract with Revenue Sharing. Management Science, 50, 34-47. 
https://doi.org/10.1287/mnsc.1030.0168

[23] Liu, P., Xie, R. and Liu, G. (2008) VMI Coordination Based on Revenue Sharing Mechanism. System Engineering, 26, 81-85.

[24] Cao, W., Li, C. and Wang, X. (2007) Analysis of Revenue Sharing Contract under VMI Environment. Journal of Management Engineering, 17, 51-55.

[25] Zhang, M. and Gao, Y. (2007) Study on VMI Model Optimization of Third Party Logistics. Journal of Management, 4, 53-56.

[26] Ma, S. and Mei, X. (2008) Analysis of the Advantages of Supply Hub Based on Risk Pooling. Logistics Technology, 27, 68-72.

[27] Zhao, D. and Lu, X. (2012) Review and Evaluation of the Development of Vendor Managed Inventory Theory. Journal of Beijing Jiaotong University (Social Science Edition), 11, 41-47. 